\title{
AS VÁRIAS ABORDAGENS DA FAMÍLIA NO CENÁRIO DO PROGRAMA/ ESTRATÉGIA DE SAÚDE DA FAMÍLIA (PSF)
}

Edilza Maria Ribeiro ${ }^{1}$

Ribeiro EM. As várias abordagens da família no cenário do programa/estratégia de saúde da família (PSF). Rev Latino-am Enfermagem 2004 julho-agosto; 12(4):658-64.

Apresenta-se o cenário que favoreceu a inclusão da família como foco de atenção nas políticas públicas. As estratégias para interromper o empobrecimento e a vulnerabilidade das famílias, no século XX, ocorrem de forma diferenciada, segundo diferentes 'Estados de Bem-Estar', nas sociedades capitalistas. Porém, ante a crise do Estado de Bem-Estar e crescente custo dos serviços públicos e privados requer-se solução familiar, ao menos parcial, em termos de reduzir a sua dependência. $O$ Programa de Saúde da Família (PSF) coloca a família nas agendas das políticas sociais brasileiras em 1994, refletindo tanto interesses do modelo neoliberal como de forças sociais solidárias. Vê-se que tal inclusão gerou multiplicidade de abordagens tais como: família/indivíduo; família/domicílio; família/indivíduo/domicílio; família/comunidade; família/risco social; família/família. Essas abordagens, por não dialogarem entre si, acabam por compor um quadro insuficientemente identificado, dificultando a assistência. Sugere-se exame das condições apontadas como forma de dar, efetivamente, vez à família.

DESCRITORES: família; programa de saúde da família; atenção primária de saúde

\section{DIFFERENT APPROACHES TO THE FAMILY IN THE CONTEXT OF THE FAMILY HEALTH PROGRAM/STRATEGY}

This study presents the scenario that favored the inclusion of the family as a care focus in public policies. The strategies to interrupt the impoverishment and vulnerability of families in the $X X^{\text {th }}$ century occur in a different form, according to different "welfare states" in capitalist societies. However, in view of the welfare state crisis and the increasing costs of public and private services and privates, at least a partial family solution is required in terms of reducing its dependency. The Family Health Program (PSF) put the family on the Brazilian social policy agenda in 1994, reflecting interests from the neoliberal model as well as from solidary social forces. This inclusion generated different approaches, such as: family/individual; family/home; family/ individual/home; family/community; family/social risk; family/family. These approaches, due to the lack of a mutual dialogue, end up composing an insufficiently identified picture, thus turning care more difficult. The conditions indicated here should be examined as a way of giving a true chance to the family.

DESCRIPTORS: family; family health program; primary health care

\section{LAS DIVERSAS ABORDAJES DE LA FAMILIA EN EL ESCENARIO DEL PROGRAMA/ESTRATEGIA DE SALUD DE LA FAMILIA (PSF)}

Este estudio presenta el escenario que favoreció la inclusión de la familia como foco de atención en las políticas públicas. En el siglo XX, las estrategias para interrumpir el empobrecimiento y la vulnerabilidad de las familias ocurren de manera diferenciada, según los diferentes "Estados de Bienestar", en las sociedades capitalistas. Por consiguiente, ante la crisis del Estado de Bienestar y el creciente costo de los servicios públicos y privados se requiere al menos una solución familiar parcial, en términos de reducir su dependencia. El Programa de Salud de la Familia (PSF) colocó la familia en las agendas de las Políticas Sociales Brasileñas en 1994, reflexionando tanto los intereses del modelo neoliberal como de las fuerzas sociales solidarias. Se vio que tal inclusión generó una multiplicidad de abordajes tales como: familia/individuo; familia/domicilio; familia/individuo/domicilio; familia/comunidad; familia/riesgo social; familia/familia. Estos abordajes, por no dialogar entre si, acaban conformando un cuadro insuficientemente identificado, dificultando la asistencia. Se sugiere un examen de las condiciones señaladas como una forma de dar, efectivamente, oportunidad a la familia.

DESCRIPTORES: familia; programa de salud de la familia; atención primaria de salud

\footnotetext{
${ }^{1}$ Enfermeira, Professor Titular da Universidade Federal de Santa Catarina, Doutoranda em Enfermagem-opção Filosofia da Saúde, Ciência e Sociedade, e-mail: edilzamr@linhalivre.net
} 
INTRODUÇÃO

\section{Oano 94, definido pela Organização das Nações} Unidas (ONU) como o "Ano Internacional da Família", constituiu-se também o marco/momento brasileiro de oficialização da família, como foco do cuidado profissional de saúde em atenção básica, através do Programa/ Estratégia de Saúde da Família* ou PSF ${ }^{(1)}$.

O PSF constitui-se como processo de reforma incremental do Sistema Único de Saúde (SUS), recebendo a missão de ser o "eixo estruturante da organização dos serviços no âmbito do sistema público de saúde no Brasil”(2)

Inicialmente formulado como programa, passa a ser definido e defendido como estratégia, especialmente a partir de 1997, data da segunda publicação do Ministério da Saúde sobre conceitos, objetivos, diretrizes e implementação do PSF.

O PSF estrutura-se em uma unidade de saúde, com equipe multiprofissional, que assume a responsabilidade por uma determinada população, em território definido, onde desenvolve suas ações. Integrase numa rede de serviços, de forma que se garanta atenção integral aos indivíduos e famílias, assegurado-se a referência e contra-referência para os diversos níveis do sistema, de problemas identificados na atenção básica ${ }^{(2)}$.

Em abril de 2003, o PSF estava implantado em 4 276 municípios brasileiros, dispondo do total de 17608 equipes de saúde da família (ESF), efetuando a cobertura de 57850891 de pessoas. Tais dados apontam para a importante difusão, interiorização dos profissionais de saúde e ampliação da cobertura da população com ações de saúde ${ }^{(3)}$.

Retomando o tema de inclusão da família na agenda da atenção básica de saúde, algumas questões podem ser apresentadas, buscando-se o entendimento dessa decisão política. Que motivações histórico-políticas impulsionaram a colocação da família nessa posição? De que família se fala? Há entendimento entre os diversos atores envolvidos no PSF, planejadores, educadores, agentes da assistência e outros, sobre a abordagem da família no contexto da atenção básica? Para incrementar o debate sobre as questões formuladas elabora-se o presente trabalho.
DESENHANDO UM CENÁRIO** PARA INCLUSÃO DA FAMÍLIA COMO FOCO DE ATENÇÃO DAS POLÍTICAS PÚBLICAS

A família vem se mantendo ao longo da história da humanidade como instituição social permanente, o que pode ser explicado por sua capacidade de mudança/ adaptação, resistência e por receber valorização positiva da sociedade e daqueles que a integram.

Destaca-se, em modelos de vida familiar adotados por diversos povos, até o final da Idade Média, a inexistência de linhas demarcatórias importantes do espaço privado, ocorrendo mais uma mescla cotidiana da vida pública e privada, favorecedoras da sociabilidade e da criação de redes de solidariedade. A partir dos meados do século XVIII, inverte-se o modelo, tornando-se a vida familiar predominantemente privada, o que favoreceu tanto o exercício da proteção social como a regulação da vida familiar $^{(4)}$.

Na França do século XVIII evidencia-se, em algumas das condições de vida dos cidadãos de classes populares, a mescla mencionada. As ruas de Paris eram repletas e movimentadas, dioturnamente, dado que muitas pessoas permaneciam em convivência nesses espaços. Aí convivia-se, jogava-se, alimentava-se, dormia-se, desfrutava-se da iluminação pública; os adultos ocupavamse ainda com as feiras e com os prazeres das tabernas e prostíbulos; quando as pessoas necessitavam de algum espaço privado alojavam-se em construções precárias, minúsculas, decadentes, ou nas vielas estreitas e escuras $^{(4-5)}$.

$\mathrm{Na}$ aristocracia, as mulheres ocupavam-se da vida política, das intrigas e com a moda. Os homens ocupavamse com treinamento militar e com questões ligadas à expansão e manutenção das conquistas territoriais. Os filhos da aristocracia eram enviados para o campo, para serem criados por amas-de-leite; ao retornarem ao convívio familiar, na adolescência, tinham preceptores que se responsabilizavam por sua educação( ${ }^{(6)}$.

Uma conjunção de condições empurra a família para organizar o seu viver, num contínuo crescente, em direção à esfera privada, tornando-se modelo hegemônico de família, nas sociedades industriais modernas, o da família conjugal burguesa. Na esfera política havia o

\footnotetext{
* A nomeação do PSF como Programa/Estratégia decorre da existência de questionamentos e argumentos a favor de ambas as identificações

** Entenda-se o termo como conjunto que compõe, representa e dialoga na composição de uma totalidade identificada
} 
interesse em reverter a alta mortalidade infantil que produzia crescimento negativo de cidadãos; requisitava-se corpos saudáveis para o processo de industrialização emergente, havendo também o interesse no controle das condições sanitárias, precarizadas pelo viver das pessoas nas ruas.

As mulheres recebem atribuições específicas na família moderna, e conseqüente valorização, ao ocuparemse diretamente dos filhos, inclusive amamentando-os, tomando medidas higiênicas com o próprio corpo e com o espaço familiar; a família passa a ter uma moradia, desocupando a rua. Os homens tornando-se trabalhadores, provedores e chefes da família. A família valoriza-se como espaço de acolhimento, segurança e cuidado, de transmissão da cultura e valores, de garantia de educação( $^{(5-6)}$.

A família conjugal moderna (família burguesa) apresenta, além da dicotomia público/privado relativa às atividades do homem e da mulher, outras características como: ser intimista, reforçando o papel da mulher como esposa e mãe, excluindo a mulher da produção; configurando o papel e status masculino ligados ao trabalho produtivo (remunerado), permitindo ao homem ser a figura principal de autoridade e da tomada de decisões ${ }^{(7)}$.

As conseqüências dessa mudança para as famílias das camadas populares será o empobrecimento e isolamento da família, pelo desmantelamento das formas de organização tradicionais e protetoras. Esse legado, do século XVIII, revela, no século seguinte, a emergência de uma problemática radicalmente nova: a despeito do progresso e da riqueza alcançados com a dinâmica da produção capitalista industrial surge a vulnerabilidade da massa. (...) ou "desafiando o otimismo liberal, uma grande parcela da população é continuamente lançada à indigência"(4).

O enfrentamento liberal da pauperização das massas no século XVIII, efetuado principalmente pela filantropia $^{(5)}$, modifica-se no final do século XIX, já que o desafio, agora posto, era o risco de desagregação do tecido social.

Através do "surgimento de uma política solidarista e, conseqüentemente, a busca de novas regras de justiça social, ocorre profundo impacto no desenho das políticas sociais". O Estado que vinha desempenhando até então papel residual e acessório passa a ser o responsável pela materialização da solidariedade, repartindo bens e serviços sociais. Adota-se a noção de risco, oportunizando a dimensionalização probabilística do social, o que permite a unificação de problemas tais como o envelhecimento, desemprego e doenças ${ }^{(4)}$.

Essa assistência do Estado, inicialmente vinculada fortemente ao trabalho, toma novos rumos, concebida como conseqüente à cidadania, visando o combate à pobreza e à vulnerabilidade social. As estratégias para interromper o empobrecimento das massas e a vulnerabilidade social no século XIX ocorrem de forma diferenciada, dependendo das configurações políticas, culturais e econômicas vigentes nas diversas sociedades.

No século XX, mantém-se o desafio de "construir sistemas redistribuitivos capazes de impedir o crescimento das desigualdades, em um contexto generalizado de mercado, como também frente aos riscos de desagregação da solidariedade social”(4).

A universalização de benefícios, modificando a assistência seletiva tradicional, possibilitou a construção de diferentes 'Welfare States' (Estados de Bem-Estar), em sociedades capitalistas, desmontados a partir dos anos 70 , quando se iniciam as transformações na esfera de produção e a internacionalização da economia, a chamada globalização.

Com a instauração de uma economia globalizada e gerenciada por organizações mundiais (FMI, BM, BID), a necessidade de adequar mecanismos e instituições de regulação torna-se prioritária na agenda política. Além de uma série de mudanças como desregulação ampla da economia, autonomia do setor financeiro, desmantelamento do setor público, a política social passa a ser encarada como uma série de medidas destinadas a compensar os efeitos negativos dos ajustes macroeconômicos realizados. O conceito de desenvolvimento social se dilui e cede terreno para o de compensação social, dando caráter meramente assistencial a determinados segmentos caracterizados pela extrema pobreza. As políticas sociais, atendendo a situações limites, assumem o papel de amortecedor das tensões sociais.

Ante a crise do Estado de Bem-Estar e crescente custo dos diferentes serviços públicos e privados "requerse a solução familiar (ao menos parcial) visando reduzir sua dependência dos serviços coletivos e aumentar ou redescobrir a autonomia e iniciativa pessoal/familiar. Configura-se o'neofamiliarismo', ou seja, a tendência ideológica de fazer da família uma unidade econômica e política, de resolução de problemas da racionalidade global do modelo neoliberal”(8). 
As possibilidades de desagregação do tecido social, traduzidas pelo abandono de mulheres e crianças, crescimento da violência, deterioração das redes de solidariedade, de ameaça de pauperização, levaram organizações internacionais a exercer pressão sobre os Estados, enfatizando "a necessidade de recuperação da importância da família como lugar de busca de condições materiais de vida, de pertencimento na sociedade e de construção da identidade"(9).

Essa pressão é evidenciada fortemente na Conferência Internacional sobre População e Desenvolvimento, realizada em setembro 1994, sob o patrocínio da ONU, no Cairo/Egito, e cujo objetivo foi concluir um Programa de Ação sobre População e Desenvolvimento, validado por 179 Estados representados. O Programa tomava por base outros encontros internacionais de peso, como a Conferência Mundial de População (1974), a Conferência Internacional de População (1984), a Conferência das Nações Unidas sobre Meio Ambiente e Desenvolvimento, a Cúpula Mundial em Favor da Infância (1990) e a Conferência Mundial de Direitos Humanos (1993).

A família é assinalada enfaticamente, no capítulo dos princípios do Programa de Ação, como unidade básica da sociedade e como tal deveria ser fortalecida. As diversas formas de família, em diferentes sistemas culturais, sociais e políticos são reconhecidas. Também se reconhece as importantes mudanças na composição e vida familiar, decorrentes do processo de rápida transformação demográfica e sócioeconômica; condições como migração e mudanças conjunturais, com rebaixamentos sócioeconômicos, aumentam as pressões sobre a família. "Recomenda-se que os governos formulem políticas sociais e de desenvolvimento que facultem o necessário apoio e proteção às famílias e respondam cabalmente às necessidades diversas e em mutação das famílias. (...) Os governos deveriam, em conjunto com ONGs e organizações comunitárias, buscar formas inovadoras de prestar assistência às famílias e indivíduos que possam estar afetados por problemas tais como extrema pobreza, desemprego crônico, violência doméstica e sexual entre outros" ${ }^{\prime(10)}$.

Os objetivos traçados com relação à família requeriam, entre outros, a elaboração de políticas e leis que apoiassem a família, que contribuíssem para a sua estabilidade, que levassem em conta sua pluralidade, que promovessem a igualdade de oportunidades para os membros da família, em especial das mulheres e crianças.
INSERÇÃO DA FAMÍLIA NO CENÁRIO DAS POLÍTICAS DE SAÚDE BRASILEIRAS

Os programas de inserção da família nos cenários das políticas públicas e de saúde brasileiras ganham impulso na década de oitenta, em função de interesses diversos, sejam do Estado, da sociedade civil ou de organismos internacionais.

No Brasil, a sociedade civil brasileira, mais especificamente as igrejas, se antecipou em relação ao Estado, estruturando e consolidando as primeiras intervenções junto à família. São exemplos disso a Sociedade São Vicente de Paula, os cursos de noivo, o Movimento Familiar Cristão, Encontro de Casais com Cristo e Pastoral da Criança ${ }^{(11)}$.

As iniciativas estatais se apresentaram como associações de pais e mestres (ligadas à rede de ensino) e os centros sociais urbanos (com clube de mães e cursos de gestantes). No Serviço Especial de Saúde Pública (SESP), fundado durante a Segunda Guerra Mundial, valorizaram-se as visitas domiciliares. Na década de 90 , voltou-se para Estatuto da Criança e do Adolescente.

A preocupação com o crescimento da violência e consolidação do conceito de famílias de risco produziu uma pauta de discussão mais ampla dos problemas familiares. Por fim, o surgimento do Programa de Saúde da Família (PSF), na década de 90, apoiado pelo Ministério da Saúde, reflete a valorização da família nas agendas das políticas sociais brasileiras. O PSF também pode ser justificado em função das mudanças sóciopolíticas operadas no País, dada à consolidação crescente da proposta neoliberal, que determina desinvestimento em saúde, em especial no âmbito hospitalar/curativo ${ }^{(11)}$.

Assim, tanto as exigências de um mundo globalizado, interessado na redução de custos dos serviços sociais e de saúde, requerendo lucros crescentes, mas, também, buscando a minimização de conflitos sociais, como as preocupações da sociedade com a desagregação social, impulsionaram a formulação, pelo Estado, de políticas públicas em direção à família, sendo o PSF uma das traduções desses movimentos.

\section{ABORDAGENS DA FAMÍLIA NO CENÁRIO DO PSF}

Analisando-se as posições emergentes de setores 
ligados ao PSF, ou sejam, oficial, acadêmico e campos da prática, é possível identificar ambivalências, diferenças, contradições, insuficiências, na forma de efetuar a abordagem da família. Na maioria das vezes, a família é abordada de forma parcelizada ou identificada através de representantes e substitutivos, ou ainda, como referência genérica no âmbito das políticas sociais e/ou é tomada como problema e transformada em objeto terapêutico ${ }^{(9)}$. $\mathrm{Na}$ relação cuidado $\mathrm{x}$ abordagem, o cuidado pode ser procedido ao indivíduo no contexto da família ou a família com um indivíduo no contexto ${ }^{(12)}$, ou ainda não ser procedido, na circunstância dessa ser apenas uma nominação adotada pelo PSF.

O estudo das três versões publicadas pelo Ministério da Saúde sobre o PSF (conceito, diretrizes, metodologia), publicados em 1994, 1997 e 2000, de textos de autores da saúde coletiva que discutiram sobre o PSF, alguns citados no corpo deste trabalho, a participação em eventos relacionados ao PSF e a experiência de trabalho da autora com tema família, desde 1990, no Grupo de Assistência, Ensino e Pesquisa em Família (GAPEFAM), impulsionaram a construção de uma categorização/abstração, sobre como está se dando a abordagem da família no PSF. Assim, propõe-se que no cenário do PSF a família esteja sendo abordada de diferentes formas quais sejam: família/indivíduo; família/ domicilio; família/indivíduo/domicílio; família/comunidade; família/risco social; família/família.

Família/indivíduo: nesta abordagem a família se concretiza na perspectiva do indivíduo, que é o foco real de atenção, podendo ser mulher, a criança, o portador de diabetes. Ou seja, a família é o cliente nominal, mas não é "objeto" do cuidado. E, ainda, a família tem papéis a desempenhar, tem deveres e responsabilidades para com o individuo em foco e para isso necessita de orientação, de treinamento. A família também é tida como aquela que interfere positiva ou negativamente no processo de saúde/ doença do indivíduo. Dado a expectativa de deveres, as condições reais de capacidade de cuidado da família, vista de forma multidimensional, são freqüentemente esquecidas, além de serem objeto de juízos de valor, por parte da comunidade e de profissionais.

Família/domicílio: nesta abordagem o ambiente, a infraestrutura material da família, as condições de cuidado desse ambiente são o foco de atenção. O substitutivo, 0 que toma lugar ou representa a família é, pois, seu espaço/ contexto físico. O domicílio é a base para a apreensão de lançamento de dados estatísticos e epidemiológicos do processo de saúde/doença, da caracterização das famílias que têm condições e daquelas que necessitam de ajuda, daquelas que requerem vigilância de saúde, ou de outras que estão em situação de risco sócioambiental.

Família/indivíduo/domicílio: nesta abordagem unemse os sentido/conteúdo de família/indivíduo e família/ domicílio, diferenciando-se por ser focado, agora, num doente presente no domicílio ou em outros indivíduos sob circunstâncias específicas do processo de saúde/doença (exemplo: a puérpera, o recém-nascido, o idoso, hipertenso, agressor). Intensifica-se a expectativa quanto a papéis, deveres, responsabilidades da família e a educação em saúde para o tratamento e cuidados do paciente. Muitas vezes essa família, envolvida em argumentos de humanização da assistência, recebe a incumbência de aliviar o oficial de sistema de saúde, enxugado/contido pelas exigências do modelo neoliberal. A exaustão da família e os efeitos nocivos dessa condição nem sempre são percebidos ou considerados. Também há resistências em se fazer correlações entre a deterioração da saúde física ou mental de membros da família (que vão desembocar nos serviços de saúde) e as situações vividas de excesso de deveres $x$ recursos limitados.

Família/comunidade: neste tipo de abordagem a família se transforma em 'as famílias'; sua identidade e processo de viver definem-se sob parâmetros universais, proveniente do contexto, da inserção social, do ambiente físico social da comunidade. Os processos são universalizados, a singularidade e a individualidade, esvaziadas. As medidas cuidativas são aplicadas às famílias. As famílias têm responsabilidade para com os problemas locais da comunidade, tais como marginalidade, violência, ou seja, agrega o enfoque de família/agente, que deve viabilizar ações através de voluntariado, associações, etc.

Família/risco social: neste enfoque a atenção está dirigida às condições de um grupo específico de famílias, geralmente aquelas em exclusão social, que vivem em comunidades periféricas. A estrutura da família, suas condições materiais e sociais de sobrevivência estão continuamente/quotidianamente problematizadas e por isso a família não consegue realizar sua missão, devendo receber ajuda para voltar a funcionar. Essas famílias são depositárias das concepções dialéticas vigentes nos espaços sociais, ou no conflito dado entre concepções protetoras/solidários/cidadãs e aquelas discriminadoras/ julgadoras/fóbicas. Os profissionais da saúde, dado as 
construções ideológicas conseqüentes à sua inserção social e formação profissional, estarão, no processo cuidativo, impactados por essas contradições.

Família/família: nesta abordagem a família é o foco principal e real da atenção considerada em sua identidade, enquanto possuidora de um plano de simbolismos, emocionalidades, racionalidades, intencionalidades, pactuações, saberes, fazeres e necessidades. O ser e viver da família ultrapassa ao que corresponderia à soma das individualidades. Essa abordagem requer consideração: das condições materiais e simbólicas, conseqüentes à inserção social da família, a sua organização e dinâmica, à disponibilidade de redes de proteção, ao desempenho social esperado, dentre outras. Requer ainda a definição do real-funcional e simbólico dos seus recursos afetivos/emocionais, espirituais, da capacidade de cuidar e cuidar-se, da sua história de fracasso $x$ sucesso para atender as demandas requisitadas em suas diferentes fases/momentos, da capacidade de avaliar, de fazer julgamentos e escolhas. Enfim a família é considerada em seu ser e viver, conseqüentes à sua inserção no contexto social, historicamente contextualizada, imersa na complexidade de ser família na pós-modernidade.

Há, pois, oportunidades de sucesso e possibilidades de riscos, para todas as famílias (de desagregação, de empobrecimento, de adição, de isolamento social, de violência, de negligências, etc.). Embora cada família tenha sua especificidade de ser e viver; também tem "zonas" de identificação com outras famílias dado as influências macrossociais. Assim, a assistência em saúde da família requer enfoque multidimensional do ser e viver família, em sua interface com o processo de saúde doença e se concretiza nos diversos ambientes por onde ela transita e em sua cotidianiedade.

\section{CONCLUSÕES}

A inclusão da família como foco de atenção básica de saúde pode ser ressaltada como um dos avanços, como contribuição do PSF para modificar o modelo biomédico de cuidado em saúde. Ultrapassa o cuidado individualizado, focado na doença; elege-se aquele que contextualiza a saúde, produzida num espaço físico, social, relacional, resgatando as múltiplas dimensões da saúde. Ressaltase que essa inclusão não decorreu de entendimento e convicção pactuadas; viu-se que a família chega à atenção primária de saúde impulsionada por diferentes e conflitantes representações e motivações, daí as facilidades de se produzirem contradições.

Mencionar a família como foco central da atenção básica de saúde não garante que isso se concretize no PSF real. Nesse cenário os diferentes atores podem trabalhar com múltiplas abordagens de família, produzindose o entendimento de que se fala e cuida de um mesmo objeto.

Mesmo o PSF tendo um caráter excessivamente prescritivo $^{(13)}$, não se encontram, em documentos oficiais, orientações sobre como conduzir a ação profissional frente às questões levantadas sobre dinâmica familiar, ou como aplicar a Teoria de Sistemas, adotada pelo PSF, mantendo a evidencia de que a família é predominantemente uma referência na atenção básica de saúde.

Mas a falta de consenso produz dificuldades de entendimento, de planejamento, no cuidado, na orientação para a formação profissional, além de frustrações pelas expectativas não atendidas.

O que decorre é que "a metamorfose dos papéis e objetivos assistenciais adere-se à indefinição de questões conceituais, principalmente, sobre família e intimidade, às dijunções presentes no conjunto assistencial do Sistema de Saúde, às fragmentações das ações de saúde junto à família decorrentes do modelo multidisciplinar adotado no processo de trabalho da ESF ${ }^{(14)}$.

Em sendo adotada, no PSF, uma multiplicidade de abordagens, que, por não dialogarem entre si ou não se complementarem, acabam por compor um quadro de diversidades/parcialidades, produzindo a questão conseqüente: como alcançar a integralidade do cuidado se quem será cuidado não está suficientemente identificado?

Por fim, ressalte-se que a proposição interpretativa configurada neste texto requer novos olhares; esses poderão contestar, modificar, ampliar as abstrações efetuadas. Análises e reflexões podem reparar insuficiências, preparando os caminhos para ações mais efetivas, exigidas ao se declarar a família o foco principal do cuidado profissional de saúde em atenção básica. 


\section{REFERÊNCIAS BIBLIOGRÁFICAS}

1. Ministério de Saúde (BR).Secretaria de Assistência à Saúde. Departamento de Atenção Básica. Anais da Reunião Técnica dos Pólos de Capacitação, Formação e Educação Permanente em Saúde da Família de 26 a 28 de Maio de 1999. Brasília (DF): Ministério da Saúde; 2000.

2. Ministério de Saúde (BR). Secretaria de Assistência à Saúde. Coordenação de Saúde da Comunidade. Saúde da Família: uma estratégia para a reorientação do modelo assistencial. Brasília (DF): Ministério da Saúde; 1997.

3. Ministério de Saúde (BR). Saúde da Família: quantos somos [citado em 31 de agosto de 2003].Disponível em http:/ / www.saúde.gov.br/psf//programa.index.asp

4. Magalhães R. Integração, exclusão e solidariedade no debate contemporâneo sobre as políticas públicas. Cad Saúde Pública 2001 mai-jun; 17(3):569-79.

5. Caponi S. Da compaixão à solidariedade: uma genealogia da assistência médica. Rio de Janeiro (RJ): FIOCRUZ; 2000. 6. Bandinter E. Um amor conquistado: o mito do amor materno. Rio de Janeiro (RJ): Nova Fronteira; 1985.

7. Coelho SV. As transformações da família no contexto brasileiro: uma perspectiva das relações de gênero. PSIQUE.

Rev Psicol da Fac de Ciências Humanas e Letras 2000 maio; 10(6):7-23.

8. Bermúdez MSM. Políticas sociales y familia. Estado de bienstar y neo-liberalismo familiarista. Fronteras 2001; (4):103-14.

9. Mioto RCT. Novas propostas e velhos princípios: subsídios para a discussão da a assistência às famílias no contexto de programas de orientação sócio familiar. Fronteras 2001; (4):93-102.

10. Organização Mundial da Saúde. Relatório da Conferência Internacional sobre População e Desenvolvimento. CairoEgito; 1994.

11. Vasconcelos EM. Educação popular e a atenção à Saúde da Família. São Paulo (SP): Hucitec/Ministério da Saúde; 1999.

12. Rocha SMM, Nascimento LC, Lima RAG. Enfermagem pediátrica e a abordagem da família: subsídios para o ensino de graduação. Rev Latino-am Enfermagem 2002 setembrooutubro; 10(5):709-15.

13. Franco T, Merhy E. PSF: contradições e novos desafios. [citado em 20 de abril 2002] Disponível em: http:// www.datasus.gov.br/cns/temas/tribunas/PsfTito.htm

14. Alonso IK. Luzes e sombras no ritual do encontro entre o universo profissional e o mundo da intimidade familiar: a intervenção profissional na saúde da família em âmbito domiciliar. [Tese]. Florianópolis (SC): Programa de Pós Graduação em Enfermagem/UFSC; 2003. 